\title{
Curriculum and Pharmacy practice experience offered for Pharm-D in Pakistan: needs and possibilities
}

\author{
*Madiha1, Chang-qing Yang ${ }^{2}$ \\ ${ }^{1}$ Madiha, College of Pharmacy, China Pharmaceutical University, Nanjing, Jiangsu, China \\ ${ }^{2}$ Chang-qing Yang, PhD, Professor, College of Pharmacy, China Pharmaceutical University, Nanjing, Jiangsu, China
}

\begin{abstract}
Pharm-D program was implemented 10 years ago in Pakistan in 2004. Since then perception of pharmacist as a health care professional became somewhat clearer among public but due to less availability of resources in Pakistan, their practice is so limited. Pharmacy Council of Pakistan has revised Pharm-D curriculum in 2011. Before this up gradation some academicians have highlighted lacking in previous curriculum, but many of them are still there in new updated syllabi. In this review we have presented a sketch of current pharmacy education and practice in Pakistan especially focusing Pharm-D curriculum. In the end by considering pharmacist's current role, limitations in Pharm-D course and already published interventions for advancing pharmacy education in Pakistan, we have discussed some major improvements required to be done in curriculum and pharmacy practice experiential component (clinical clerkship) offered for Pharm-D degree in Pakistan.
\end{abstract}

Key Words: Pharm-D, Curriculum, Clinical clerkship, Pakistan.

\section{INTRODUCTION}

Today the world is facing growing health issues, where some of them are due to wrong use of the drugs. It has been an accepted fact that pharmacists can help to prevent these drugs related problems thus helping to improve health of the masses. Clinical pharmacy has further elaborated the role of the pharmacists and thus many countries have upgraded their pharmacy curriculum and focused it from mere dispensing role to providing a complete pharmaceutical care service. In this review we have summarized the current undergraduate pharmacy education and pharmacy practice in Pakistan. We have also discussed various aspects of Pharm-D curriculum like the core curriculum and pharmacy practice experience (clinical clerkship). In the end, by considering the already published work and interventions, various possible ways to upgrade pharmacy education in Pakistan are given.

\section{Pharmacy Education in Pakistan}

In 1948 University of Punjab was the first institution to start 3 years bachelors of pharmacy program. Pharmacy education remained unattended until Pharmacy Council of Pakistan was established in 1967, a professional body responsible for regulating registration of pharmacist and promotion of pharmacy education in Pakistan. It provides a complete set of rules and regulations along with the unified Pharm-D curriculum for all the pharmacy institutes. Three years undergraduate program was extended to 4 years B-Pharm degree in 1978-1979 which was later upgraded to (Doctor of pharmacy) Pharm-D 5 year program in 2004 (Azhar et al., 2010). The National Curriculum Revision Committee (NCRC), Higher Education Commission Pakistan has approved the revised Curriculum for Doctor of Pharmacy (Pharm-D) Program

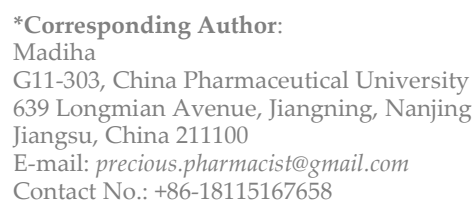

in 2011. Recently in 2013 Federal Government of Pakistan has also approved this revised curriculum. If we look at the number of institutions, there is a clear increase over period of time. Till 2000, not more than 10 public universities were offering a B-Pharm course. While now, 18 public sector universities \& 15 private sector universities are authorized to offer Pharm-D program \& 17 institutes have recently received no objection certificate (NOC) in this regard (Pharmacy council of Pakistan, 2014). In Pakistan both annual \& semester system are available where mostly later is more common. All Pakistani pharmacy institutions (universities or colleges) are required to follow the Higher Education Commission (HEC) approved Pharm-D svllabus, which is the essential requirement for accreditation from Pharmacy council of Pakistan

\section{Pharmacy Practice in Pakistan}

According to WHO 2012, total population of Pakistan has reached $179,000,000$ and population growth rate is $1.8 \%$ (WHO, 2012). Compared to this the total health facilities available are insufficient. A view of human resources in health sector of Pakistan is given in figure 1 (WHO EMRO Demographic \& Health Indicators, 2010). As a developing country in past few years Pakistan has faced various socioeconomic crises and progress in health sector is indeed slow. Still somehow a constant effort is done by Government to manage the situation.

Health care services provided in hospitals and clinics in Pakistan have a very prominent role of physicians assisted by nurses. Pharmacist's duties are mostly being performed by nurses, mid-wives, lady health workers and other paramedical staff (National Health Policy Pakistan, 2009). Pharmacists are recognized as the third largest health care providers group in the World (FIP-News from the Federation, 2005). But their role is still not established in Pakistan. Number of pharmacist available is 0.9 per 10,000 populations, that is too much less than the ratio required by WHO 1:2000.

Figure 2 shows percentage of pharmacists working in different areas of current pharmacy practice in Pakistan. 


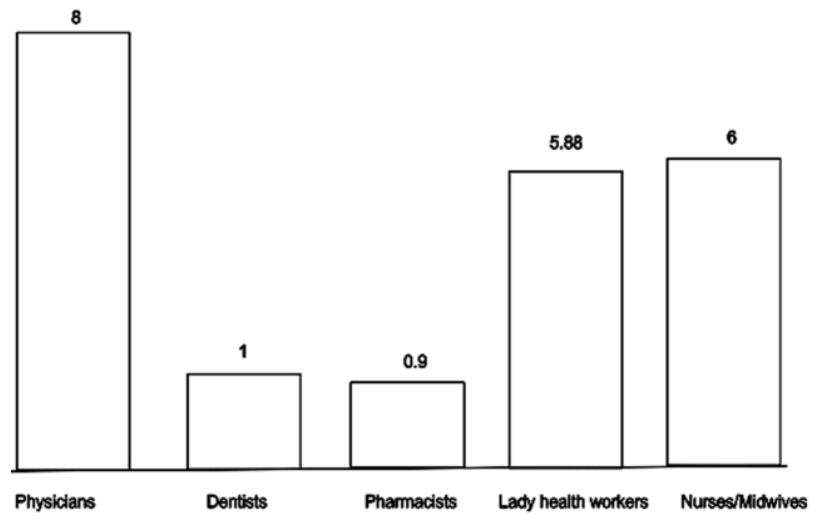

Figure 1: Human resource for health in Pakistan (WHO EMRO Demographic \& Health Indicators, 2010).

Pharmacists in Pakistan mostly work in industrial or sales sector, although Government is trying to create more job opportunities for pharmacists in hospitals but unless the clear role of hospital pharmacist is not identified by other health care professionals, pharmacists themselves and official authorities, this effort is useless. This is the reason that even after 10 years of Pharm-D implementation, clinical pharmacists are still struggling for their rights to practice in the hospital as an essential part of the patient care team. In Pakistan, medicines are mostly dispensed through medical stores run by pharmacy technicians or assistants and less through pharmacies, whereas there are only 0.43 registered pharmacies available per 10,000 of populations (Pharmaceutical country profile of Pakistan, 2010).

Unfortunately availability of qualified pharmacist in these registered pharmacies is mostly doubted. Which results in unsatisfactory pharmacy services provided to the masses for example substitution of generic equivalents at the point of dispensing is allowed in public sector facilities, but not in the private sector. Antibiotics and injectables are sold over the- counter without a prescription (Butt et al., 2005). Even a research has showed that more than $50 \%$ people said they were able to get medicine without prescription (Azhar et al., 2012).

\section{PHARM-D CURRICULUM IN PAKISTAN}

\section{Distribution of Credits among Different Courses}

According to the official curriculum, there are five basic departments required to be established in every pharmacy institute and 26 pharmacy subjects are taught under them. While three general courses Pakistan studies, Islamiat and English are also taught (Pharm-D curriculum, Pharmacy council of Pakistan, 2013). Unlike Pharm-D in USA, there is no concept of pre-pharmacy in Pakistan although a premedical intermediate education is needed to get enrolled in pharmacy. Total credit hours required for 5 years of Pharm-D course are 198, where 158 are assigned for the theoretical courses and 40 are for practical work. We have given a figure (figure 3) to demonstrate these departments, courses \& credit hour distribution between theory and practical. There is no room for the changes in the curriculum provided by Pharmacy Council of Pakistan and there are no electives available.

\section{Pharmacy Practice Experiential Work}

In USA, according to ACPE (Accreditation Council for Pharmacy Education) guidelines, Pharm-D curriculum is divided into core curriculum, introductory pharmacy

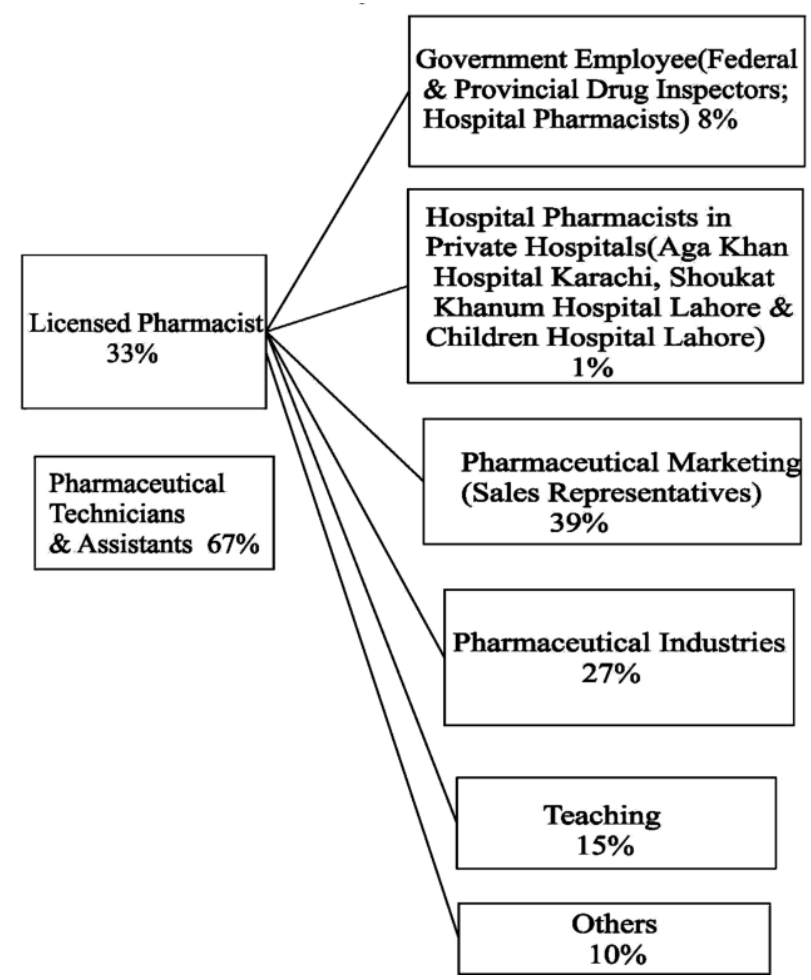

Figure 2: Percentage of pharmacists working in different areas of current pharmacy practice in Pakistan (Pharmaceutical country profile, 2010) (Murtaza, 2010).

practice experience IPPE should not be less than $5 \%$ and advanced pharmacy practice experience APPE should not be less than $25 \%$. Ambulatory care practice, community pharmacy practice, intensive care unit orientation is also focused along with hospital based practice. Although Pakistan has adopted Pharm-D concept by following USA but there is no clarity regarding pharmacy practice experience (PPE). If we consider official document for syllabus published by Pharmacy council of Pakistan, there is no practical work for community pharmacy or hospital pharmacy courses and as for clinical pharmacy practical, a clinical clerkship and project completion is mentioned. It also encompasses drug or prescription evaluation. Altogether credit hours for practical work of pharmacy practice related courses is $3.03 \%$ of total curriculum, where clinical pharmacy has 4 credit hours ( 2 credit hours for $4^{\text {th }}$ year and 2 for $5^{\text {th }}$ year) that would not be more than $2.02 \%$ of total curriculum. Percentage of Theory and Practical work, based on credits hours assigned for five major departments in curriculum is shown in figure 4 .

In order to obtain Pharm-D degree, it is required to complete a clinical pharmacy clerkship. As no structured or organized plan is given for clerkship in official curriculum, different universities have established their own clerkship programs by collaborating with hospitals in their vicinity. For example, Islamia University Bahawalpur, a public university, where author studied Pharm$\mathrm{D}$, have devised very structured practice model. Students are divided in various groups to visit Bahawal Victoria Hospital. In $4^{\text {th }}$ year students perform prescription evaluation at hospital/community pharmacy. They also need to complete a research project in group. While in $5^{\text {th }}$ year, during hospital orientation they visit different wards and fill following reports e.g. Pharmacist clinical ward 


$\begin{aligned} & \text { Pharmaceutical } \\ & \text { Sciences }\end{aligned}$
Physical Pharmacy(6/2)
Dosage Form Sciences(6/2)
Pharmaceutical Microbio-
biology \& Immunology(6/2)
Industrial Pharmacy(6/2)
Biopharmaceutics \&
Pharmacokinetics(6/2)
Pharmaceutical Quality
Management(6/2)
Pharmaceutical
Technology(6/2)

\begin{tabular}{ll|}
$\begin{array}{l}\text { Pharmceutical } \\
\text { Chemistry }\end{array}$ & \multicolumn{1}{c|}{$\begin{array}{c}\text { Pharmacy } \\
\text { Practices }\end{array}$} \\
$\begin{array}{l}\text { Organic Chemistry(6/2) } \\
\text { Biochemistry(6/2) }\end{array}$ & $\begin{array}{l}\text { Pharmaceutical Maths(3) } \\
\text { Pharmaceutical Analysis(6/2) }\end{array}$ \\
Medicinal Chemistry(6/2) & $\begin{array}{l}\text { Dispensing Pharmacy(3/1) } \\
\text { Community, Social \& } \\
\text { Administrative Pharmacy(3) }\end{array}$ \\
& $\begin{array}{l}\text { Computer \& its applications } \\
\text { in Pharmacy(3/1) } \\
\text { Pharmaceutical Marketing \& } \\
\text { Management(6) }\end{array}$ \\
& Hospital Pharmacy(6)
\end{tabular}

Clinical Pharmacy(I \& II) (12/4)

Forensic Pharmacy(6)

\begin{tabular}{|c|}
\hline $\begin{array}{c}\text { Basic Medical } \\
\text { Sciences }\end{array}$ \\
\hline Physiology(6/2)
\end{tabular}

\begin{tabular}{|c|}
\hline Pharmacognosy \\
Pharmacognosy(I \& II) \\
$(12 / 4)$
\end{tabular}

Anotomy \& Histology(3/1)

Pharmacology \&

Therapeutics(12/4)

Pathology(3/1)

Figure 3: Pharm-D curriculum in Pakistan.

report, Pharmacist ward round report, Farm notes, Prescription translation, Lab findings. They present case histories during class discussions, where teacher evaluate their performance. A private institution, Dow College of pharmacy at Dow University of Health Sciences, with affiliated teaching hospital have established well organized clinical clerkship under the supervision of clinical pharmacist, in a research published by the institution, students were regularly rotated to hospital where they were trained to take medication histories, review patient profiles, gather \& interpret laboratory data, and identifying drug related problems. Then they have to present the case studies in interactive discussions with clinical pharmacists. This is proved to be a very efficient tool for developing effective clinical skills in students (Muttaqi et al., 2012).

\section{DEFICIENCIES AND POSSIBLE SOLUTIONS}

Academicians and researchers have identified various shortcomings in Pharm-D curriculum and clinical clerkship offered in Pakistan, and they have also given different possible way outs to improve pharmacy education in Pakistan. Some issues can also be sorted out by using techniques that have already been implemented and accessed in other regions.

\section{Related to Core-Curriculum}

It is an established fact that in Pakistan, pharmacists have more job opportunities in industrial sector and so it needs to be more focused, but if we look at curriculum, pharmaceutical sciences have 7 courses with 56 credit hours, is much more than other subjects, even more than pharmacy practice with 8 courses that are so diverse and different from each other. The credits distribution should be managed to avoid repetition or duplication of content in

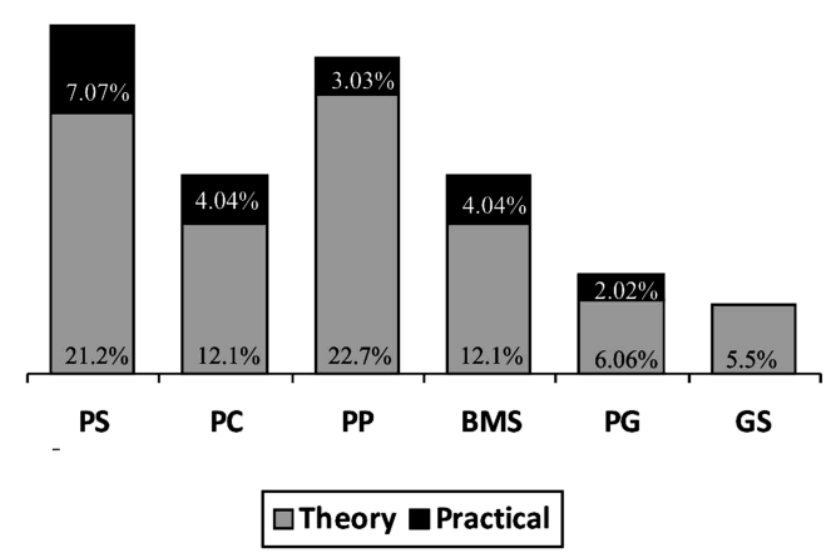

PS: Pharmaceutical Sciences, PC: Pharmaceutical Chemistry PP: Pharmacy Practice, BMS: Basic Medical Sciences PG: Pharmacognosy, GS: General Subjects

Figure 4: Percentage of Theory and Practical work based on credit hours assigned to six major departments in curriculum.

courses. A Pharm-D degree must have a curriculum including multidisciplinary courses, so that students can distinguish their role as pharmaceutical care providers instead of simple drug dispensers (Jamshed et al., 2007).

Clinical pharmacy has not given a status of separate department in curriculum instead it is included in pharmacy practice department. A lot of debate has been done on this issue. Some have related it to the policy of individual universitv or lack of required staff with sound clinical pharmacy background (Hadi and Hughes, 2009). But we hope this will be possible in near future, as this will help in hiring of teachers specifically qualified in the field of clinical pharmacy, and establishment of graduates program for clinical pharmacy in universities. Some researchers have also suggested that young academicians should be sent to developed countries to get higher education in new subjects of pharmacy, and well reputed foreign faculty members should be hired (Murtaza et al., 2010). This can be an effective way to develop clinical pharmacy departments in universities.

A nationwide unified Pharm-D curriculum is indeed praiseworthy effort of Pharmacy Council of Pakistan but universities should be encouraged to experiment some innovative courses. A private institute has developed a two hour lecture for the final year student on the Healthcare System of Pakistan with special emphasis on Generic Medicine Utilization (Khalid and Fazal, 2011). Another way is to introduce some elective courses in curriculum such as psychology or behavior sciences, which can help establishing a better foundation for their later professional career.

While formulating curriculum, it is mostly copied from foreign resources and sometimes it is ignored that if the health care institutions or settings in that particular developing country itself have sufficient facilities to enable students to practice what they have learned in class (Khan, 2010). Khan et al. (2011) has presented a systemic way for the curriculum designing and validation in the form of Pharmacy Curriculum Development and Validation Model (PCDVM) that can be a guideline for the pharmacy educators. A group of researchers have also proposed a curriculum for Pharm-D with some specialized courses and more proportion of pharmacy practice 
experience (Murtaza et al., 2010). Each university can implement a curriculum evaluation system, involving teachers and students, and an annual report should be sent to pharmacy council. These reports should be considered during curriculum development, as it will ensure maximum participation and formulating a needs based curriculum.

\section{Related to pharmacy practice experiential work}

Pharmacy practice courses have less practical work than theoretical, as it is just $3.03 \%$ of total curriculum. In clinical oriented programs, clerkships play an important role in effective training and evaluation of students. And if less percentage of grades is assigned to these patient care activities, it would be difficult to evaluate students' clinical skills (Khan, 2010).

There is no practical work for community pharmacy, hospital pharmacy or pharmaceutical management and marketing courses. This mav limit student understanding of their future role in public health. If we consider reasons for not indulging community pharmacy orientation, the fact is that mostly pharmacies in Pakistan are unable to provide community services to public as: 1) dispensing rights are given to physicians who have established their medical stores along with their clinics hiring nonprofessionals 2). Mostly pharmacists rent out their license to laymen for a monthly payment, who runs the medical store/retail/community pharmacy in a non-professional way. It is the responsibility of Government or other regulatory authorities to implement rules and regulations and try to enforce them (Khan, 2011). Even though a research conducted regarding perception of general population about pharmacist showed that although only $50 \%$ of people are satisfied with pharmacist's role at pharmacies, still more than $70 \%$ of population believes that pharmacist can guide them regarding their medication (Azhar et al., 2012). It must be understood that pharmacist can only create his better perception by providing efficient services to public through pharmacies. If students will not learn how they can participate in these settings, they will remain reluctant and same illegal dispensing practice will be continued. Some very good pharmacy chain set ups are established in different cities, universities can collaborate with them to allow students practice there.

In Pakistan, only few private hospitals have hired clinical pharmacists with defined clinical roles. While in the Government sector, although now more job opportunities are created for pharmacists in hospital, but these hospital pharmacists are only involved in dispensing or updating hospital formulary, and merely perform a clinical role. So it is difficult to give students suitable environment, well equipped with required role of clinical pharmacists such as counseling or patient education. But simulations can be used like establishing drug information center or clinics in the pharmacy departments, where students can practice in groups with simulated patients. Many studies conducted in other countries showed that use of simulations for teaching the skills related to pharmacy practice can help transferring knowledge to a better patient care (Sandra and Pamela, 2011). Service learning can also be used like creating awareness among public about some diseases or setting up blood donation camps. Service learning help students become competent and caring health care workers. A studv have showed that students who took part in service learning, learned more in areas important for pharmacy education (Kevin, 2013).
Most important thing is to analyze the current situation or availability of pharmacy practices in hospitals or what steps should be taken to improve, than specify in curriculum what students can do in hospitals wards. There must be contact hours mentioned. If once in a week than students must know how much hours they need to spend in different wards performing different tasks like taking patient histories, checking ward formulary, determining ADRs of drugs used in wards etc.

There are no guidelines regarding preceptors or their role. Mostly only teachers are preceptors who guide, monitor or evaluate the students. The shortage of preceptors is a global problem. In Pakistan, doctors perceive pharmacists as drug information experts but mostly they do not appreciate pharmacists providing direct patient care (Azhar et al., 2010). Still Pharmacy Council of Pakistan can make an effort to persuade doctors associations to provide preceptor ship. On the other hand as Government is hiring more and more hospital pharmacists, if thev are given well-structured and outcome-oriented training, they can be good clinical preceptors. A paper is published by a private pharmacy institute, as they have developed a specialized clerkship program under supervision of physicians and clinical pharmacists for the students of 4 th and 5 th year. They observed that the students learned patient counseling, utilizing different sources of drug information, cost effective drug dispensing, reporting adverse drug events and collaborating with either physicians or nurses in a professional manner (Aslam and Ahmad, 2011). Another approach not mostly considered in pharmacy institutes in Pakistan is that a senior peer student can play a particularly important role by serving as mentors to junior students. This approach can promote a belief of selfregulation and a "collegial consciousness" (Bucher and Stelling, 1977).

In Pakistan, actual problem is lack of proper communication among different governing bodies. It was suggested that a national university for pharmaceutical sciences can be established, that should be responsible for evaluating Pharm-D programs, distinguishing the role of pharmacists from pharmacy assistants, and ensuring the availability of pharmaceutical care. This kind of institution can increase coordination between pharmacy institutes, pharmaceutical industries and Pharmacy Council of Pakistan (Babar, 2006).

\section{CONCLUSION}

No doubt there are some flaws in Pharm-D syllabi, and most of these are due to the limited space given to pharmacist in health care sector of Pakistan thus leading to insufficient learning or practice opportunities for undergraduate students. But like developed countries, it will take time to establish proper clinical role of pharmacists in Pakistan. An effort is needed on every level, from pharmacy institutes, teachers, students, to professional pharmacists like hospital pharmacists, community pharmacists, industrial pharmacists and especially a strong contribution is required from governing bodies such as Pharmacy Council of Pakistan, Pakistan Pharmacist Association, and Ministry of health and Government of Pakistan to upgrade and strengthen pharmacy education and profession as it is the need of modern health care system in the world. 


\section{REFERENCES}

Aslam N and Ahmed KZ. Clinical pharmacy clerkship in Pakistan: a leap from paper to practice. Innovations in pharmacy. 2011; 2(2): 39

Azhar S, Hassali MA, Ibrahim MIM, Ahmad M, Imran Masood, Shafie AA The role of pharmacists in developing countries: the current scenario in Pakistan. Hum Resour Health. 2009; 7(1): 54. [DOI]

Azhar S, Hassali MA, Ibrahim MIM. Doctors' perception and expectations of the role of the pharmacist in Punjab, Pakistan. Tropical Journal of Pharmaceutical Research. 2010;9(3): 215-222. [DOI]

Azhar S, Hassali MA, I. Hussain. Evaluating the Perception of General Public towards the Role of Pharmacist in Health Care System of Pakistan.Value in Health. June 2012; 15(4): 199. [DOI]

Babar Z. Pakistan's National University of Pharmaceutical Sciences. Am J Pharm Educ. 2006 October 15; 70(5): 123.

Bucher, R. and Stelling, J.G., Becoming Professional, Sage Library of Social Research, Volume 46, Beverly Hills CA (1977).

Butt ZA, Gilani AH. Nanan D, Sheikh AL, White F. Quality of pharmacies in Pakistan: A cross-sectional survey. International Journal for Quality in Health Care. 2005; 17(4): 307-313. [DOI]

FIP-News from the Federation. 2005; Vol 19(No.2) 2005

Hadi MA and Hughes J. Broader Perspective Needed on the PharmD Degree in Pakistan. Am J Pharm Educ. 2009; 73(6): 114. [DOI]

Jamshed S, Babar ZD, and Masood I. The PharmD Degree in Developing Countries. Am J Pharm Educ. Dec 15, 2007; 71(6): 125. [DOI

Kevin R. Kearney. Impact of a Service-Learning Course on First-Year Pharmacy Students' Learning Outcomes. Am J Pharm Educ. Mar 12, 2013; 77(2): 34. [DOI]

Khan TM. Critical Considerations in Pharmacy Curriculum Development in South Asian and Southeast Asian Developing Nations. Am J Pharm Educ. 2010 November 10; 74(9): 176g.
Kahn TM. Challenges to Pharmacy and Pharmacy Practice in Pakistan. Australas Med J. 2011; 4(4): 230-235. [DOI]

Khan TM, Anwar M, Mueen Ahmed KK. A perspective for clinical pharmacy curriculum development and validation in Asian developing nations. J Young Pharmacists 2011; 3: 151-4. [DOI]

Khalid S, Fazal. The Pharm.D in Pakistan: A Curricular Innovation in Health Systems Instruction. Innovations in pharmacy. 2011; 2(1)1: Article 26

Murtaza G, Ahmad M, Iqbal M, Khan SA, Ejaz M, Yasmin T. Pharmacy Education and Practice in Pakistan: A Guide to Further Development Hacettepe University Journal of the Faculty of Pharmacy. 2010; 30(2):139-156

Muttaqi SSSA, Shamim S, Omer M. Practicing hospital pharmacists mentoring pharmacy students in clinical pharmacy: An experience from Dow University of Health Sciences (DUHS) Pakistan. IRJP (2012); 3 (4): 148-149

National Health Policy 2009 (Stepping Towards Better Health). Government of Pakistan, Ministry of Health (National Health Policy Unit). [Link] [Accessed on 20 Jan 2014]

Pharmacy council of Pakistan. [Link] [Accessed on 10 Jan 2014]

PharmD curriculum. Pharmacy council of Pakistan. [Link] [Accessed on 10 Jan 2014]

Pharmaceutical Country Profile of Pakistan. Ministry of Health. Pakistan 2010. [Link]

Sandra L. Kane-Gill, Pamela L. Smithburger. Transitioning Knowledge Gained From Simulation to Pharmacy Practice. Am J Pharm Educ. 2011 December 15; 75(10): 210. [DOI

WHO EMRO Demographic \& Health Indicators, 2010. [Link] [Accessed on 20 Jan 2014]

World Health Organization. [Link] [Accessed on 18 Jan 2014] 